\title{
IDONEIDAD DEL INJERTO CORNEAL DE DONANTE NEONATO EN LA QUERATOPLASTIA PENETRANTE
}

\section{SUITABILITY OF NEWBORN DONOR CORNEAL GRAFT IN PENETRATING KERATOPLASTY}

\author{
BELMONTE $\mathrm{J}^{1}$, MORAL $\mathrm{R}^{2}$, VALLCANERA $\mathrm{S}^{2}$
}

\section{RESUMEN}

Objetivo: El límite inferior de edad del donante corneal resulta polémico. A pesar de la mayor densidad endotelial neonatal existen problemas quirúrgicos (anatomía corneal infantil), refractivos (tendencia a miopización) y postoperatorios (mayor inmunogenicidad). Se analizan dos casos con empleo de tejido donante de 4 meses, con resultado refractivo postoperatorio atípico en ambos y desproporcionada respuesta inmune en uno. A propósito de los mismos, se realiza una revisión sobre el uso de injertos de donantes pediátricos en la queratoplastia penetrante.

Métodos: Se presentan dos pacientes jóvenes con queratocono intervenidos de queratoplastia penetrante con injerto donante de 4 meses y alta densidad endotelial $\left(4.500 \mathrm{cel} / \mathrm{mm}^{2}\right)$.

Resultados: En el postoperatorio inmediato presentaron una elevada hipermetropía (se redujo posteriormente) con escaso astigmatismo. En uno aumentó notablemente el astigmatismo tras la excisión de sutura precisando queratotomía arcuata y puntos de refuerzo, mostrando al año y medio injerto transparente, agudeza visual corregida de $\mathrm{V}=1 \mathrm{y}$ densidad endotelial alta $\left(4.300 \mathrm{cel} / \mathrm{mm}^{2}\right)$. El otro presentó a los 7 meses un rechazo con edema del

\section{ABSTRACT}

Objective: The lower recommended age of the donor cornea is a controversial matter. Although newborn corneas have a high endothelial cell density, there are anatomical, refractive (myopic shift) and postoperative problems. Two cases are analyzed; one had an atypical refractive result and the other an unexpectedly severe immune response. We also review the use of pediatric donor corneas in penetrating keratoplasty.

Methods: Two young patients with keratoconus, in whom a penetrating keratoplasty was done using a 4month-old newborn corneal donor with high endothelial cell density $\left(4.500\right.$ cell $\left./ \mathrm{mm}^{2}\right)$ are reported.

Results: In the early postoperative period, both had high hypermetropy with weak astigmatism that improved over the next few months. In one patient a marked increase in the astigmatism after removal of the continuous suture was observed. One and a half years after the penetrating keratoplasty there was $\mathrm{V}=1$ corrected vision and the endothelial population was almost unchanged $\left(4,300 \mathrm{cell} / \mathrm{mm}^{2}\right)$. The other patient suffered an allograft reaction with corneal oedema in the seventh postoperative month, and subsequent rupture of the continuous suture made its early removal necessary. The oedema par-

\footnotetext{
Recibido: 2/4/07. Aceptado: 15/2/08.

Servicio de Oftalmología. Hospital General Universitario Alicante. España.

1 Doctor en Medicina.

2 Licenciado en Medicina.

Correspondencia:

José Belmonte Martínez

Servicio de Oftalmología

Hospital General Universitario de Alicante

Avda. Pintor Baeza, 12

03010 Alicante

España

E-mail: belmonte_jos@gva.es
} 
injerto y poco después aflojamiento y rotura de la sutura obligando a su escisión precoz. Pese al intenso tratamiento el edema cedió solo parcialmente.

Conclusiones: El injerto neonatal puede originar una fuerte hipermetropía inicial, contrario a la supuesta y descrita miopización, aunque parece reducirse paulatinamente. El moderado astigmatismo inicial cambia notablemente tras la escisión de sutura. La más rápida cicatrización en jóvenes puede provocar un aflojamiento precoz de la sutura. El riesgo de rechazo irreversible parece superior, presumiblemente, por una mayor inmunogenicidad. El empleo de córnea neonatal es cuestionable, debido a su impredecible respuesta refractiva e inmune.

Palabras clave: Queratoplastia penetrante, neonato, injerto corneal, donante, hipermetropía. tially diminished with high doses of steroids, but still persisted eighteen months later.

Conclusion: The newborn corneal graft might have led to an early strong hypermetropy as opposed to the supposed myopic shift referred to in the literature. The extremely rapid healing seen in young recipients may lead to early loosening of the continuous suture. High endothelial cell density increases the risk of irreversible graft failure probably due to a high antigenic response.

The use of a newborn donor cornea is questionable due to unpredictable refractive and immunological responses (Arch Soc Esp Oftalmol 2008; 83: 219 230).

Key words: Penetrating keratoplasty, newborn infant, corneal graft, donor, hypermetropy.

\section{INTRODUCCIÓN}

El establecimiento de los márgenes de edad de la córnea donante constituye una cuestión polémica entre diferentes bancos de ojos y cirujanos sin que por el momento se haya llegado a un criterio unánimemente aceptado (1-3).

Si bien el límite superior de la edad del donante ha sido fijado alrededor de los 75 años, los estándar médicos de la Eye Bank American Association (EBAA) lo subordinan al juicio del cirujano y del director del Banco de Ojos, condicionándolo a la potencial viabilidad del tejido corneal y singularmente del endotelio, dependiente sobre todo de su densidad celular, comprobable por microscopía óptica o especular (4).

En relación al límite inferior de edad, la mayoría de los centros aceptan tejidos que provienen de donantes pediátricos por encima de los 6 meses. En este caso el criterio no es dependiente de la población endotelial, en principio muy elevada en la infancia y que, supuestamente, proporciona una mejor protección del injerto frente a una posible pérdida intra y postoperatoria, sino al intento de minimizar diversos problemas: a) técnicos, asociados al trasplante de un tejido inmaduro, b) funcionales, derivados de una diferencia en el tamaño y de una mayor curvatura de la córnea del niño que puede influir en el resultado visual al provocar una fuerte miopización del injerto o, finalmente, c) clínicos, dependientes de una supuesta mayor capaci- dad antigénica del tejido infantil que incrementaría el riesgo de rechazo inmune y consiguientemente la viabilidad y transparencia definitiva del trasplante.

Se presentan dos casos en los que se empleó la córnea de un neonato de 4 meses observándose en ambos un resultado refractivo postoperatorio inicial hipermetrópico atípico y en uno de ellos una desproporcionada respuesta inmune. A propósito de estos dos casos, se realiza una revisión sobre el uso de injertos de donantes pediátricos en la queratoplastia penetrante.

\section{SUJETOS, MATERIAL Y MÉTODOS}

El donante fue un lactante varón, de 4 meses de edad, fallecido por muerte súbita. El intervalo entre el fallecimiento y la enucleación fue de una hora y media, conservándose en el ojo izquierdo el globo fresco en nevera a $4^{\circ} \mathrm{C}$, con la finalidad de emplearlo para heterotrasplante de células límbicas, realizándose en el ojo derecho la escisión de un botón córneo-escleral introducido en medio de conservación Optisol ${ }^{\circledR}$. El período de mantenimiento fue en ambos casos de 36 horas. La evaluación endotelial con microscopio especular de Banco de Ojos (Konan EKA-98) fue en el ojo izquierdo (OI): 4.950 $\mathrm{cel} / \mathrm{mm}^{2}$ y en el ojo derecho (OD): $4.934 \mathrm{cel} / \mathrm{mm}^{2}$ (fig. 1). El diámetro corneal era en ambos de $10 \mathrm{~mm}$.

La primera receptora fue una mujer de 16 años con queratocono bilateral, más marcado en ojo 


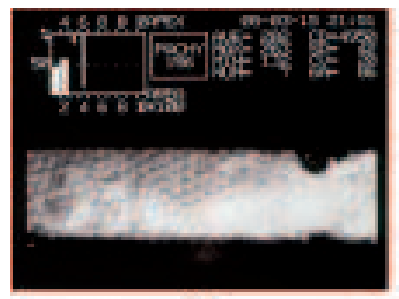

OI

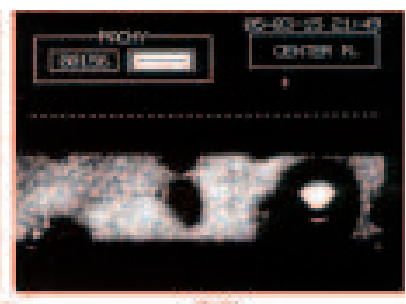

OD
Fig. 1: Córnea donante de neonato de 4 meses de edad. Diámetro corneal $10 \mathrm{~mm}$ en ambos ojos. Microscopía endotelial: OI: $4.950 \mathrm{cel} / \mathrm{mm}^{2}$; OD: $4.934 \mathrm{cel} / \mathrm{mm}^{2}$.

izquierdo, que presentaba una agudeza visual con lentes de contacto de $\mathrm{OI} V=0,5$ y $\mathrm{OD} V=0,6$, con mala tolerancia a las mismas. La topografía corneal mostraba en ojo izquierdo una ectasia temporal inferior, con un astigmatismo de 8,26 D y en ojo

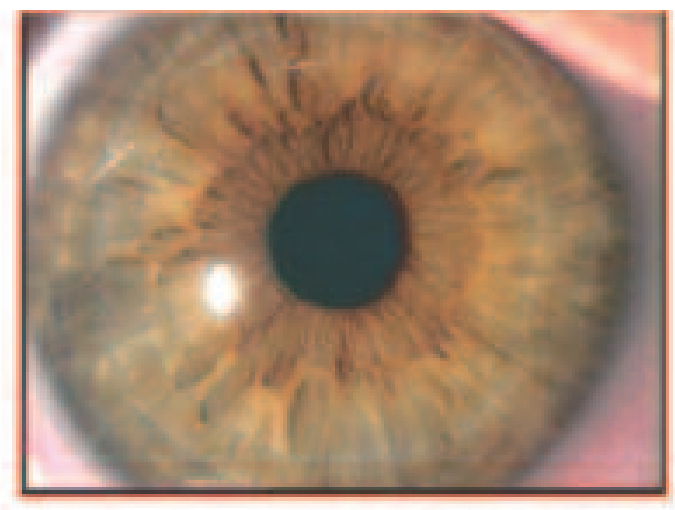

A

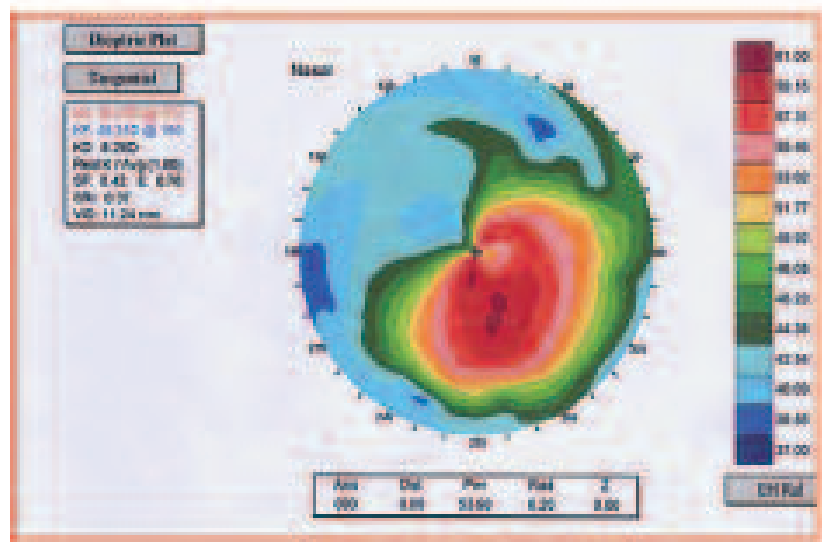

derecho una ectasia paracentral inferior con un astigmatismo de 7,0 D (fig. 2). La microscopía endotelial reflejó unas cifras de $2.915 \mathrm{cel} / \mathrm{mm}^{2}$ en ojo izquierdo y $2.957 \mathrm{cel} / \mathrm{mm}^{2}$ en el derecho. Fue intervenida, bajo anestesia general, de queratoplastia penetrante del ojo izquierdo, realizándose en el donante una trepanación por la cara epitelial en el globo completo fresco, con trépano manual de 7,5 $\mathrm{mm}$, y del mismo diámetro en la córnea receptora, con trépano de Barron-Hessburg, sin incidencias. Se realizó una sutura continua con nylon monofilamento $10 / 0$, con reajuste final bajo queratoscopio quirúrgico $\left(\mathrm{Nevyas} 360^{\circ}\right)$. El curso postoperatorio fue normal aplicándose durante un mes una medicación tópica de antibiótico y corticoide, seguida durante un año de corticoide tópico en dosis decreciente.

El segundo receptor fue un varón de 18 años con queratocono bilateral, portador de lentes de contacto. La agudeza visual con corrección en el ojo dere-
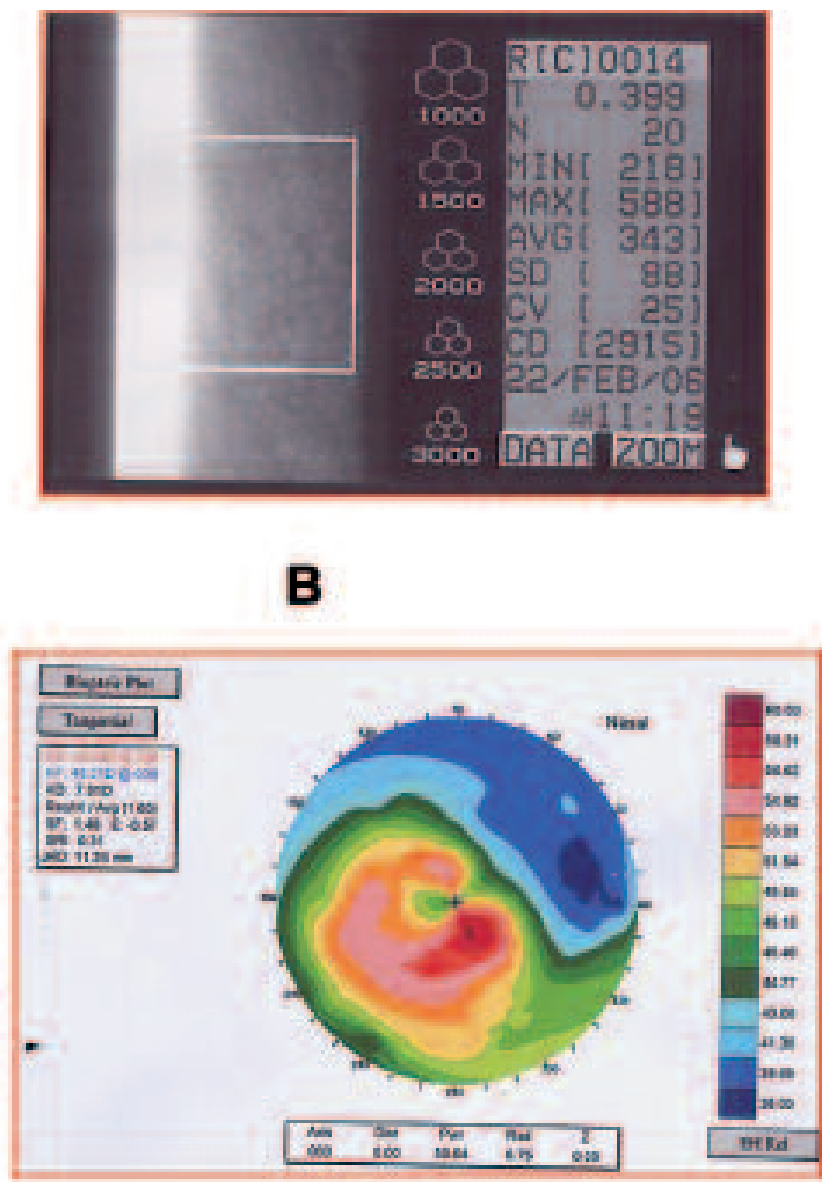

Fig. 2: Paciente 1. Mujer de 16 años. Queratocono en ambos ojos. A: Ojo izquierdo; B: microscopía endotelial OI (2.915 cel/mm²); C: topografía corneal OI; D: topografía corneal OD. 
cho era de $V=1$ y en el izquierdo de $V=0,05$. En el ojo izquierdo se apreciaban estrías de cara posterior y una ligera opacidad difusa en zona paracentral inferior. La topografía corneal mostraba un fuerte queratocono central en el ojo izquierdo con un astigmatismo de $25 \mathrm{D}$ (KS: 67,89 D; KF: 42,21 D) $\mathrm{y}$ en el ojo derecho un leve queratocono inferior $\mathrm{y}$ moderado astigmatismo (KS: 44,19 D; KF: 42,10 D) (fig. 3). La microscopía endotelial era de 2.971 $\mathrm{cel} / \mathrm{mm}^{2}$ en el ojo izquierdo. Fue intervenido bajo anestesia general de queratoplastia penetrante del ojo izquierdo, seccionándose el botón córneo-escleral donante con un punch de Barron de 7,5 mm por la cara endotelial y del mismo diámetro $(7,5 \mathrm{~mm})$ en el receptor con trépano de Barron-Hessburg, sin incidencias. El injerto fue fijado con sutura continua de nylon monofilamento 10/0, reajustándose mediante control con el queratoscopio quirúrgico $\left(\right.$ Nevyas $360^{\circ}$ ). El curso postoperatorio fue normal, prescribiéndose medicación antibiótica y corticoide tópica durante cuatro semanas y luego sólo colirio corticoide en dosis decreciente.

\section{RESULTADOS}

Al mes de la intervención, la primera paciente presentaba injerto trasparente, un moderado astigmatismo y un fuerte defecto esférico hipermetrópico (+2 cil $120+8$ esf) con cuya corrección la agu-
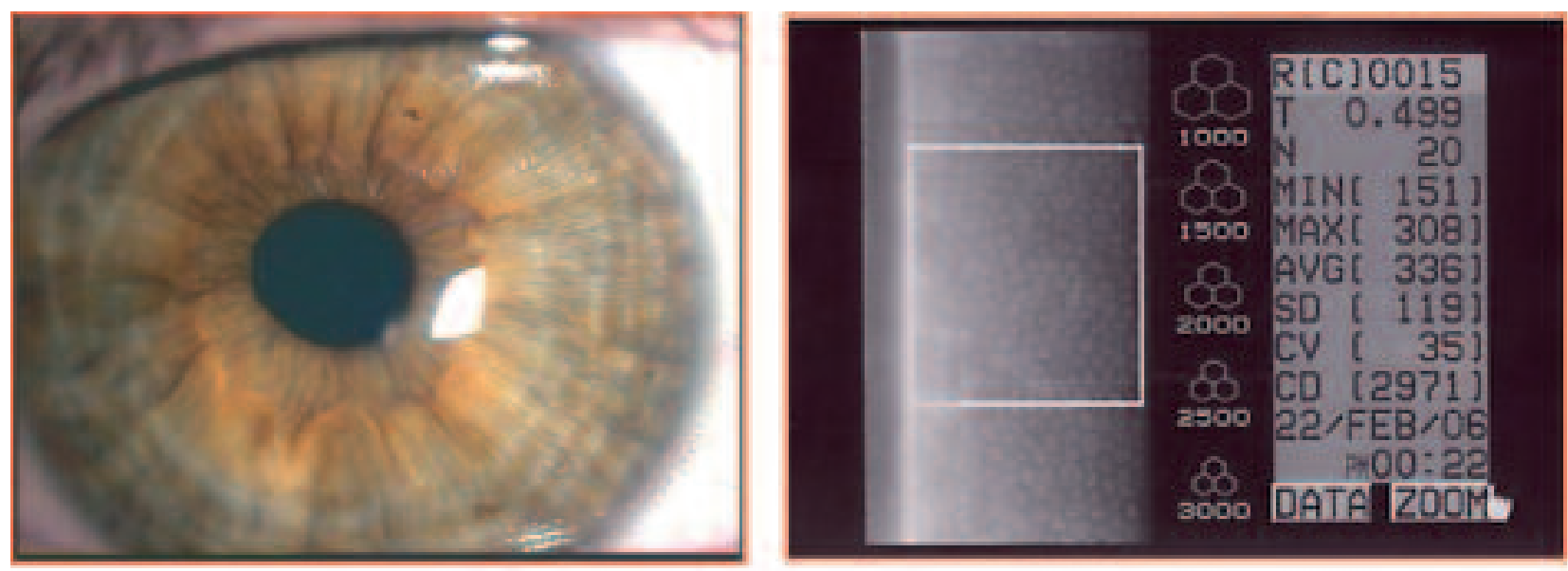

A
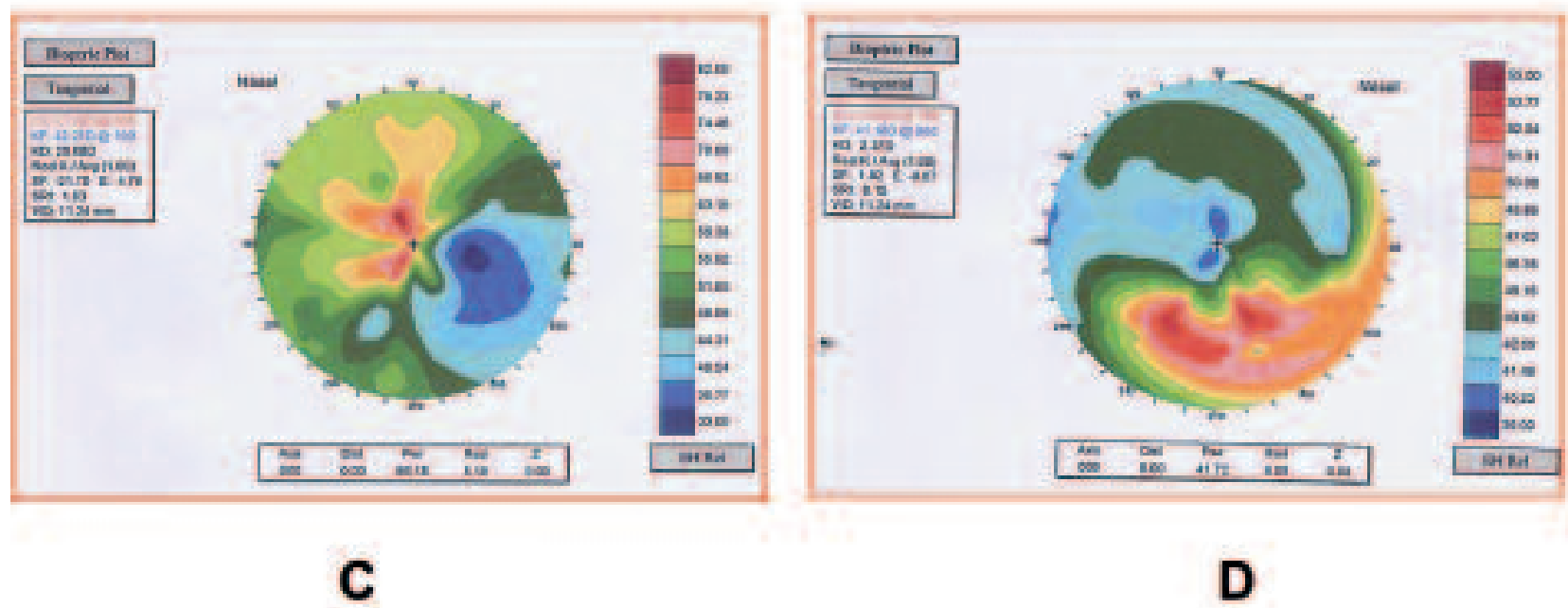

Fig. 3: Paciente 2. Varón de 18 años. Queratocono en ambos ojos. A: ojo izquierdo; B: microscopía endotelial OI; C: topografía corneal OI; D: topografía corneal OD. 
deza visual era de $\mathrm{V}=0,7$. La topografía indicaba un notable aplanamiento del injerto (KS: 39,49 D./ KF: 35,41 D.) (fig. 4). Los controles posteriores mostraron escasas modificaciones, con transparencia del trasplante persistiendo un astigmatismo moderado y sólo una discreta reducción de la hipermetropía con valores queratométricos algo más elevados. A los 11 meses se apreciaba una moderada reducción de la hipermetropía inicial $(+1,75$ cil 100 $+5,50$ esf), con incremento de las cifras de queratometría (KS: 42,45 D./KF 40,27 D), siendo la agudeza visual con corrección de $\mathrm{V}=1$. La biometría mostraba una longitud axial de 21,54 mm (22,08 mm en el derecho); la tensión ocular era de 10 $\mathrm{mmHg}$, la paquimetría de $507 \mu \mathrm{m}$, y la microscopía endotelial daba una densidad celular de 4.941 cel $/ \mathrm{mm}^{2}$, coincidente con la medición preoperatoria de la córnea donante (fig. 5). Al año de la intervención se realizó la escisión de la sutura continua, tras la que se produjo una notable modificación con marcada elevación del astigmatismo hasta 12,12 D (KS 53,38 D/KF 41,26 D) (fig. 6) alcanzando, no obstante, una AV corregida $\mathrm{V}=1\left(+12\right.$ cil $60^{\circ}-3,50$ esf), no prescribiéndose en aquel momento gafas correctoras. A los dos meses de la extracción de la sutura se practicaron queratotomías arcuatas en el

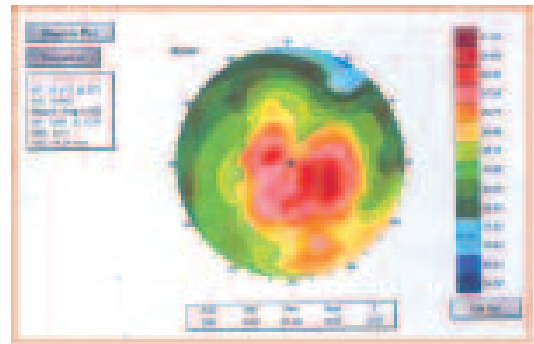

WS XS.4PD/ KF. 35.41 D

A

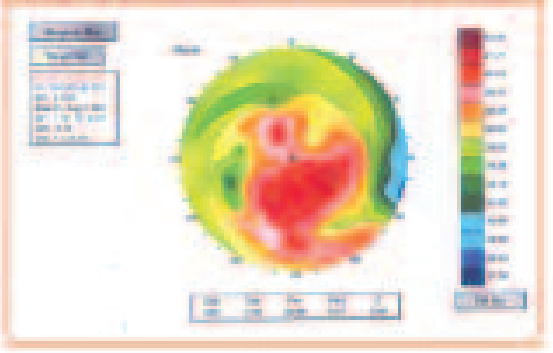

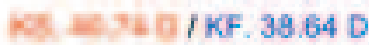

B

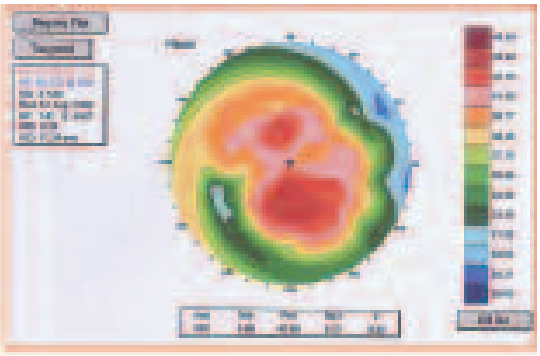

KS Q8 450 / KF 40.27 D

C

Fig. 4: Paciente 1. Variación de la topografia corneal. A: a los 12 meses; B: a los 6 meses; C: al año.

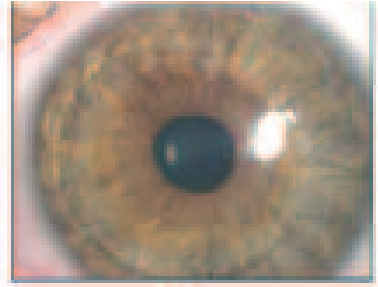

A

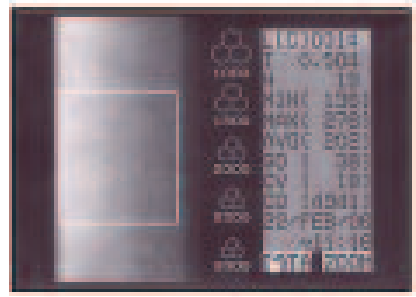

B

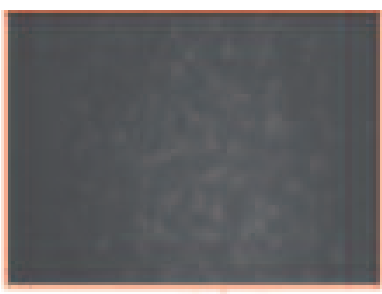

C

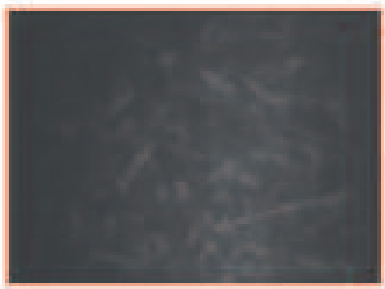

D

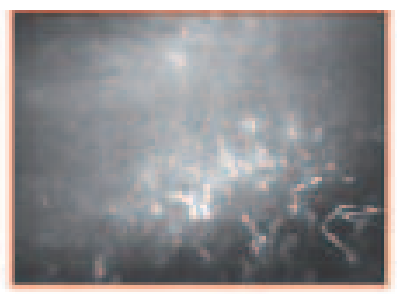

E

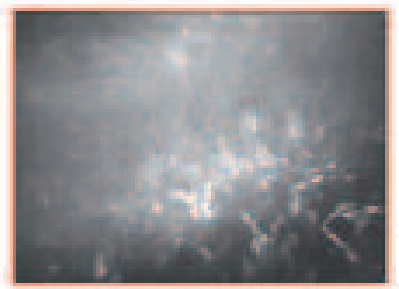

F

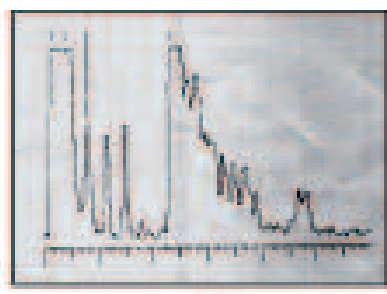

G

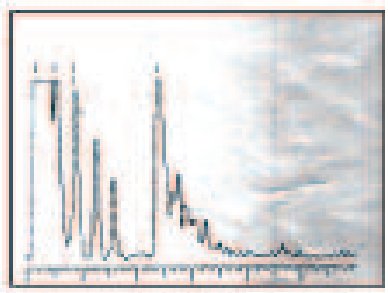

$\mathrm{H}$

Fig. 5: Paciente 1. Situación al año de la queratoplastia del OI. A: injerto transparente, sutura continua estable; B: microscopía endotelial $\left(4.941 \mathrm{cel} / \mathrm{mm}^{2}\right)$. C, D, E y F: microscopía confoca; G: longitud axial OI (21,54 mm); F: longitud axial $O D(22,08 \mathrm{~mm})$. 

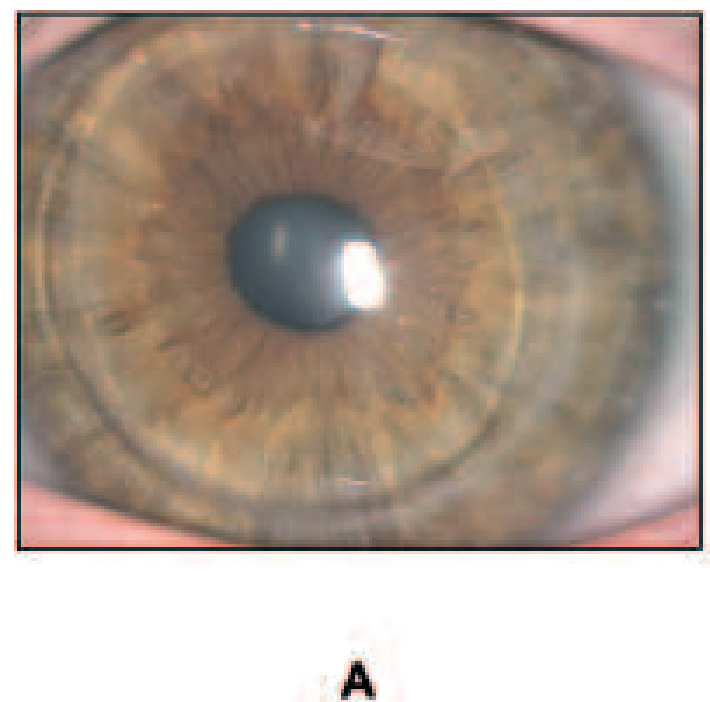

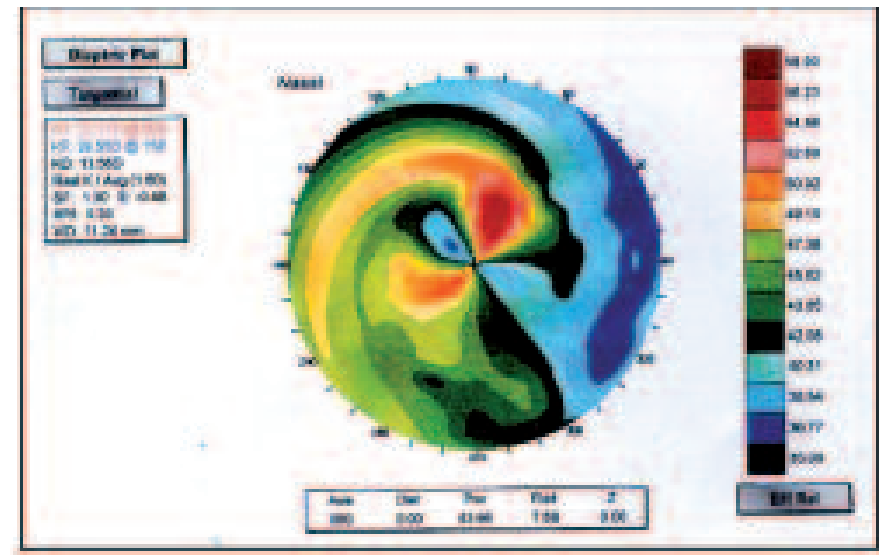

KB. Se $110 / \mathrm{KF} .38 .55 \mathrm{D}$

B

Fig. 6: Paciente 1. Situación tras la escisión de la sutura continua al año de la intervención. A: injerto transparente; B: marcado incremento del astigmatismo.

meridiano de mayor curvatura, $0,5 \mathrm{~mm}$ por dentro de la interfase, de $70^{\circ}$ de amplitud, con puntos de refuerzo con monofilamento $10 / 0$ en el meridiano opuesto, reduciéndose el astigmatismo notablemente (algo menos de $8 \mathrm{D}$ ) hasta un valor de 4,6 D (KS $47,44 \mathrm{D} / \mathrm{KF} 42,78 \mathrm{D})$ y mostrando, tras escindir los puntos de refuerzo, una agudeza visual con correc- ción $(+4,50$ cil $65-0,50$ esf) de $V=1$. Al año y medio del trasplante persistía la transparencia del injerto presentando un astigmatismo estable de 4,6 $\mathrm{D}$ con un incremento de la curvatura corneal (KS 50,41 D / KF 45,72 D) (fig. 7) que aumentaba el componente miópico del astigmatismo mixto, reduciéndose significativamente la hipermetropía inicial
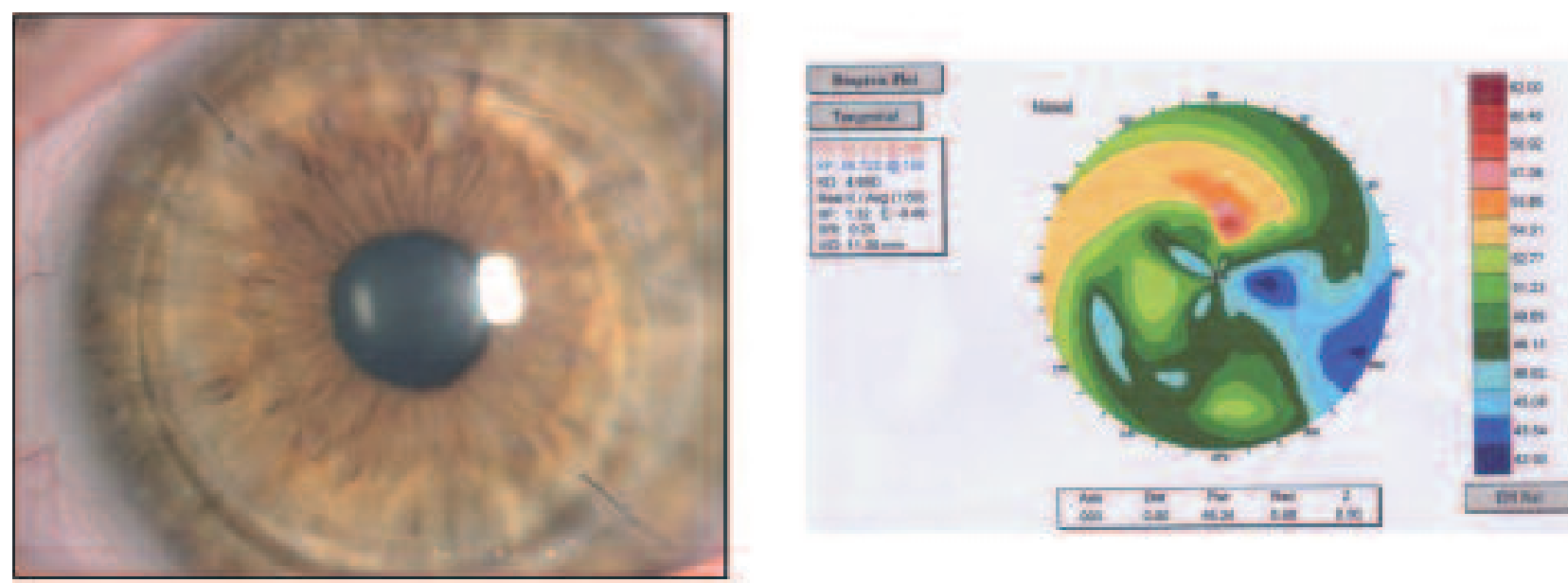

KE: 09.41 D/KF: 45.72

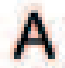

Fig. 7: Paciente 1. A: queratotomía arcuata con puntos de refuerzo; B: topografía al año y medio del transplante y tras la cirugía correctora del astigmatismo. 
(+ 4,50 cil $65^{\circ}-2,50$ esf), con una agudeza visual corregida de $\mathrm{V}=1$. La microscopía especular mostraba una densidad endotelial algo menor de 4.300 $\mathrm{cel} / \mathrm{mm}^{2}$.

El segundo paciente mostraba al mes de la operación injerto transparente, sutura estable, un astigmatismo leve, una fuerte hipermetropía esférica y un marcado aplanamiento corneal (KS: 33,07 D; KF: 29,29 D), alcanzando con su corrección (+3 cil. $110^{\circ}+7$ esf.) una agudeza visual de $\mathrm{V}=0,7$. A los 6 meses persistía el defecto hipermetrópico, reduciéndose el aplanamiento, aunque incrementándose el astigmatismo (KS: $40.91 \mathrm{D}$; KF: $34.91 \mathrm{D}$ ) (fig. 8) persistiendo con la corrección de gafas (+ 6 cil 80 +2 esf) la misma agudeza visual de $\mathrm{V}=0,7$. Habiendo interrumpido el tratamiento corticoide tópico, a los 7 meses, acudió de urgencias por referir desde 4 días antes borrosidad de visión en el ojo trasplantado que fue tratado previamente en otro centro con un colirio de tobramicina y dexametasona (Tobra$\left.\operatorname{dex}^{\circledR}\right)$, Ciclopléjico tópico y Deflazocort $30 \mathrm{mg}$ oral (Zamene ${ }^{\circledR}$ ). El examen ocular mostraba un marcado edema difuso por rechazo endotelial (fig. 9), aplicándosele un tratamiento adicional con una megadosis única intravenosa lenta de $500 \mathrm{mg}$ de metilprednisolona $\left(\right.$ Urbason $^{\circledR}$ ) y la instilación frecuente (cada hora) de un colirio de dexametasona (Maxidex $\left.{ }^{\circledR}\right)$. En días sucesivos se mantuvo el tratamiento tópico intenso sin observarse una apreciable mejoría. Al mes, y manteniendo el tratamiento tópico para el rechazo, acudió nuevamente de forma urgente por sensación de cuerpo extraño y secreción mucosa, continuando la córnea edematosa y comprobándose la rotura de la sutura continua entre las IX y XI horas, con los extremos distales de los hilos enterrados en parénquima y sin aparente neovascularización. No obstante, a los 10 días se procedió a escindir la sutura continua, manteniéndose la terapia con corticoides tópicos frecuentes. En los controles sucesivos se comprobó una ligera mejoría aunque persistiendo el edema que impedía la realización de microscopía endotelial y confocal, injerto engrosado con una paquimetría de $902 \mu \mathrm{m}$ (ojo derecho $578 \mu \mathrm{m}$ ) y una tensión ocular de $20 \mathrm{mmHg}$ (ojo derecho $15 \mathrm{mmHg}$ ), longitud axial de 24,14 $\mathrm{mm}$ (ojo derecho de $24,53 \mathrm{~mm}$ ). La topografía corneal mostraba un incremento del astigmatismo hasta $10,28 \mathrm{D}$ con escasa variación de la curvatura (KS: 41.08 ; KF: 30.80 D) y una agudeza visual de 0,1 . Se mantuvo el tratamiento tópico con corticoides en dosis descendente. Al año y medio de la intervención la topografía muestra modificaciones con un marcado incremento del astigmatismo (26,28 D), observándose una mejoría del edema que persiste en la porción central del injerto con periferia transparente. No puede realizarse evaluación de la densidad endotelial ni mediante microscopía especular ni confocal. Por el momento se decide esperar la evolución antes de plantear una nueva queratoplastia.

\section{DISCUSIÓN}

Desde un punto de vista anatómico la córnea del neonato difiere notablemente de la del adulto tanto en sus magnitudes anatómicas como en sus peculiaridades estructurales y funcionales.

El promedio de diámetro corneal del recién nacido a término es alrededor de $10 \mathrm{~mm}$, todavía menor en los prematuros $(5,6)$ incrementándose rápidamente hasta alcanzar unos valores entre 11,6 y 11,7 $\mathrm{mm}$ al año de edad (7-10) próximos a los $12 \mathrm{~mm}$ del ojo desarrollado. $\mathrm{Su}$ espesor $(0,57 \mathrm{~mm})$ es algo menor que en el adulto $(0,6 \mathrm{~mm})$ aunque Insler (11)

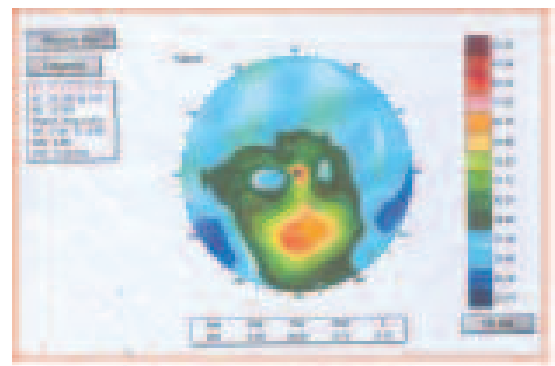

33.07 D

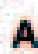

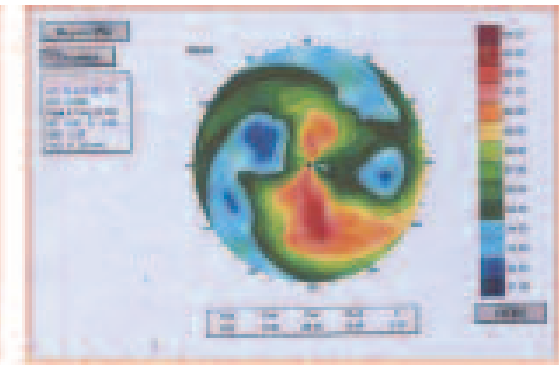

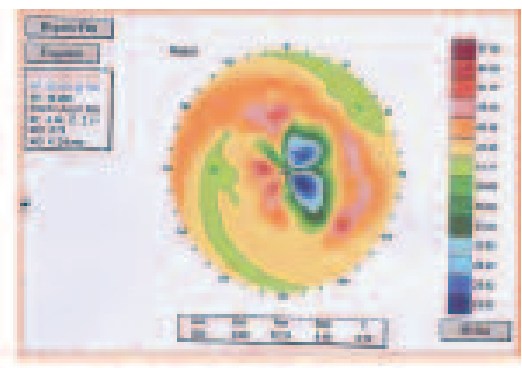

52. $43910 / \mathrm{KF} .34 .91 \mathrm{D}$
KEA130 / KF. $30.80 \mathrm{D}$

Fig. 8: Paciente 2. Topografía corneal. A: a los 3 meses; B: a los 6 meses; C: al año. 


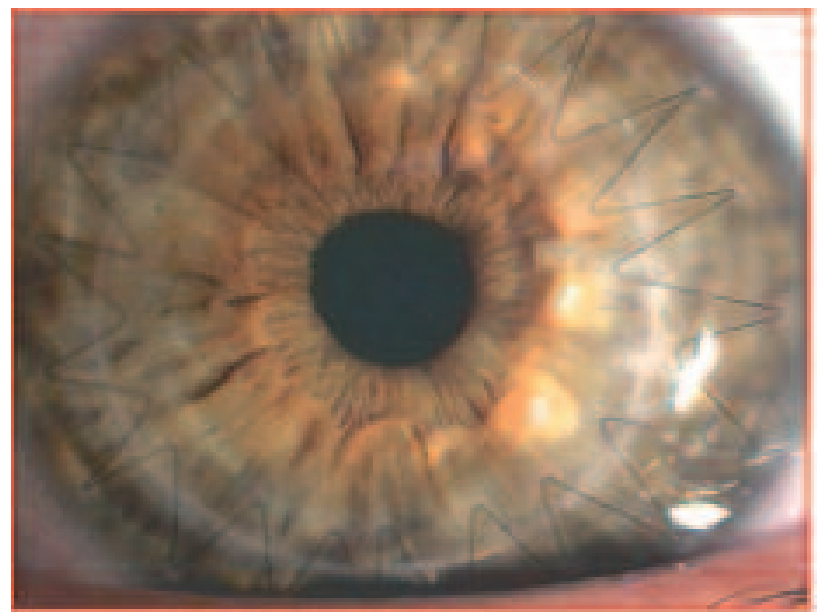

A
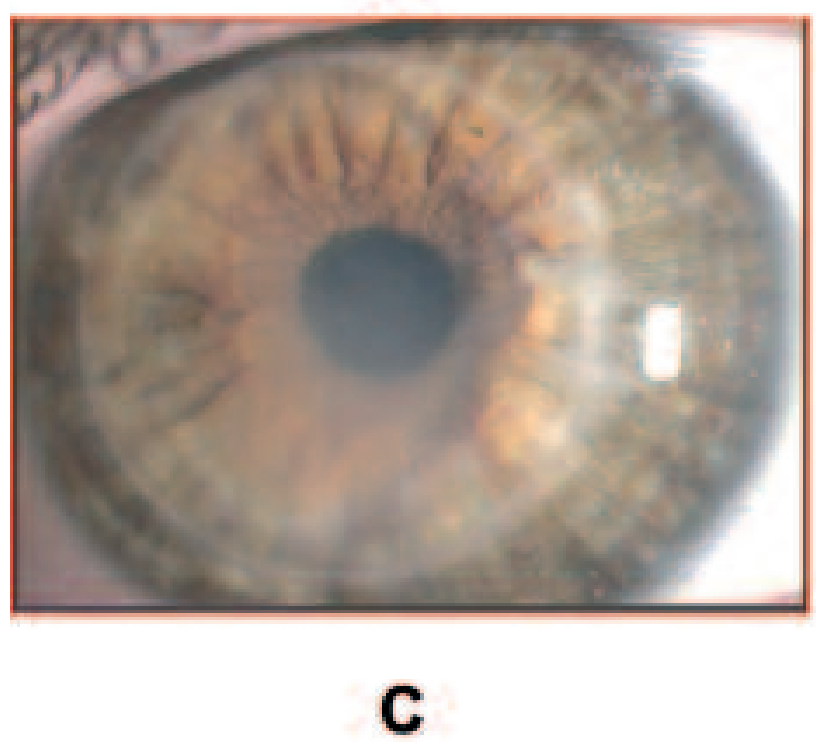

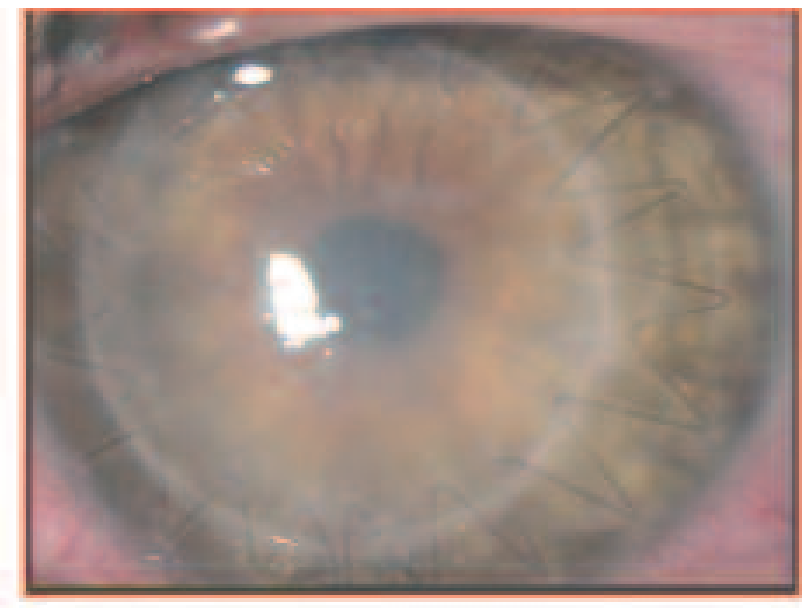

B
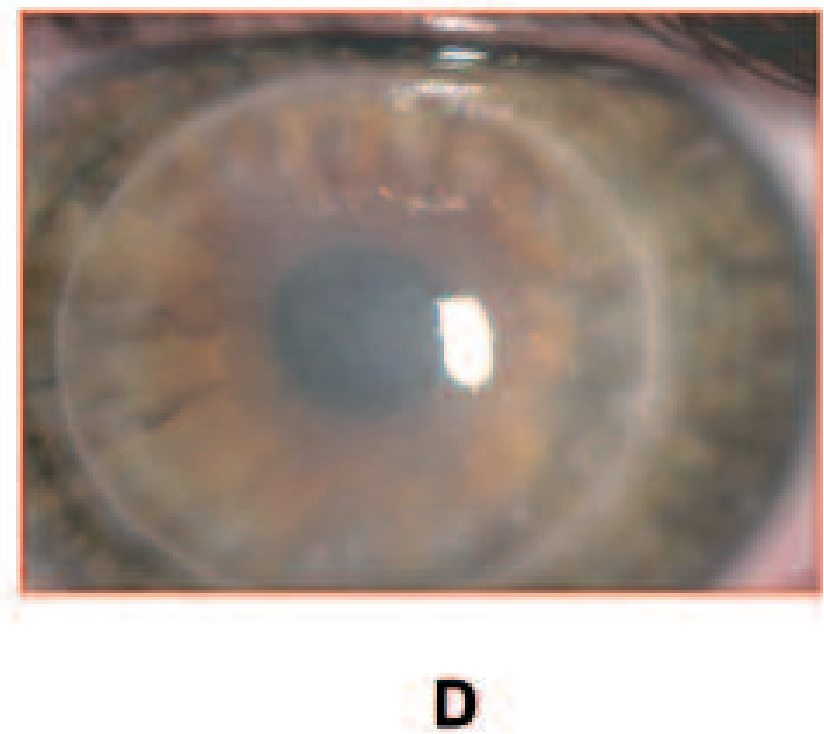

Fig. 9: Paciente 2. A: injerto transparente a los 6 meses; B: rechazo endotelial (8 meses), además del injerto mantenimiento de la sutura; C: ligera mejoría del edema tras la escisión de la sutura (10 meses); D: persistencia del edema al año y medio.

encuentra unos valores parecidos no hallando correlación con la mayor curvatura. El radio de curvatura es de $7 \mathrm{~mm}$ aproximadamente (9) e incluso inferior (11) lo que provoca un mayor poder dióptrico pareciendo existir una correlación entre el radio y la menor longitud axial que compensaría la hipermetropía esperable en el niño (9). Se ha comprobado un marcado aumento de la curvatura corneal en niños prematuros (de unas 53-54 D), que experimenta un notable aplanamiento durante el período correspondiente a los últimos meses de gestación
$(12,13)$. En el nacido a término la curvatura de la córnea es también más elevada que en el adulto, con un poder de alrededor de $47 \mathrm{D}(10,12-14)$ que desciende en los 6 primeros meses. Si bien el diámetro de la córnea aumenta durante el período postnatal, deteniéndose a partir de los 2 años, la curvatura corneal parece estabilizarse más precozmente, alcanzando los valores del adulto a lo largo del segundo semestre de vida $(10,12,13,15-17)$.

Estructuralmente el estroma muestra unas características particulares en la primera infancia. En el 
nacimiento los elementos celulares son relativamente numerosos si bien durante los primeros 2 ó 3 años de vida postnatal el número de corpúsculos corneales descienden gradualmente y el entramado de colágeno es más pobre aumentando de un modo proporcional los elementos fibrosos (18). Esta circunstancia, posiblemente necesaria para lograr un adecuado proceso de emetropización del ojo, le confiere a la córnea del recién nacido una mayor flexibilidad y elasticidad en comparación con el ojo desarrollado. La naturaleza de la matriz estromal corneal del niño es, sin embargo, desconocida en parte (10).

No cabe duda que la densidad celular endotelial es mucho mayor y muestra una morfología más regular en el neonato y en la infancia que en el adulto (19-22). Bahn (23) refiere cifras de densidad celular en el neonato de hasta $6.000 \mathrm{cel} / \mathrm{mm}^{2}$ que desciende dramáticamente en el período postnatal precoz especialmente coincidiendo con el aumento del diámetro corneal. Speedwell (24) entre niños comprendidos entre 6 días y 12 meses encuentra una gran variabilidad oscilando entre 2.987 y 5.624 $\mathrm{cel} / \mathrm{mm}^{2}$, estos últimos siempre en menores de 2 meses. Müller y Doughty (25) estudiando una serie, comprendida entre 5 y 15 años, obtienen unos valores medios de 3.542 (DE 510) células $/ \mathrm{mm}^{2}$ (rango 2.404 a 4.817). Aunque el aumento del diámetro corneal reduce la densidad endotelial al tenerse que acoplar a una superficie mayor (26), existe una gran variabilidad en los resultados de diferentes estudios sobre los cambios en la población celular endotelial a lo largo de la vida. Si bien hay una reducción celular por unidad de área en la infancia durante el primer año, no está muy claro si se debe a una variabilidad individual de la densidad celular en el nacimiento (24,26-28), a una pérdida celular, al crecimiento corneal o a todos estos fenómenos asociados $(19,23,29,30)$; aunque parece que el incremento del diámetro es un determinante esencial (21,23,31-36).

El menor tamaño de la córnea del lactante, su marcada flexibilidad, su mayor curvatura y poder dióptrico y su alta densidad endotelial, condicionan una particular respuesta tisular e inmune que puede originar una serie de problemas básicamente quirúrgicos, refractivos y clínicos.

\section{A) Problemas quirúrgicos}

El menor diámetro corneal del niño supone una limitación en el tamaño del botón córneo-escleral donante y dificulta técnicamente su trepanación que, necesariamente, debe estar muy bien centrada para evitar incluir en el injerto tejido escleral, trabecular, restos conjuntivales o episclerales del ojo donante.

Resulta especialmente necesaria una correcta colocación intraestromal de las suturas, idealmente a nivel predescemético. Los puntos demasiado profundos, inadvertidamente transfixiantes, pueden causar perforaciones, susceptibles de potenciales complicaciones como microfiltraciones de la incisión y atalamia, aumentando el riesgo de endoftalmitis. Por el contrario, los puntos demasiado superficiales pueden desgarrar el tejido, perdiendo parcialmente su efecto a ese nivel, pudiendo provocar elevados astigmatismos o inducir una dehiscencia posterior de la incisión.

Una córnea infantil demasiado delgada, situada sobre un lecho receptor edematoso y engrosado, puede originar una significativa disparidad en el espesor donante-receptor, causando una deficiente aposición de la membrana de Descemet de ambos, potenciada por su posible retracción tras la trepanación debido a su más pobre trama colágena, que puede dar lugar a un desaconsejable escalonamiento del borde de la herida y una mayor incurvación del injerto (10) .

La excesiva curvatura del botón córneo-escleral del lactante puede también causar incidentes durante la trepanación por su cara endotelial con punch. Al tener el bloque de teflón un radio relativamente más plano, acorde con el promedio del ojo adulto, la mala adaptación a su lecho provoca presiones inadecuadas en el centro del injerto creando pliegues endoteliales, secciones con mayor diámetro del previsto o un corte biselado de los bordes, sólo evitables realizando la trepanación por la cara epitelial en el globo completo.

\section{B) Problemas refractivos}

Si bien la mayor flexibilidad de la córnea infantil permitiría en teoría asumir más precozmente un contorno normal en el postoperatorio y proporcionar una recuperación visual más rápida, esa extremada elasticidad, la mayor delgadez y la mayor curvatura pueden provocar, por el contrario, defectos de refracción residuales excesivamente elevados.

En este sentido, se considera que la complicación refractiva más importante asociada al uso de corne- 
as infantiles es posiblemente la inducción de una miopía postoperatoria $(37,38)$. Vannas $(39)$ describe una miopía severa cuando emplea córneas de recién nacidos. Wood (40) nota una refracción miópica relacionándola con la mayor curvatura de la superficie corneal anterior. Por esta razón, en una etapa anterior al uso común de lentes intraoculares asociada a la queratoplastia, se sugirió el empleo de córneas infantiles como una posible alternativa quirúrgica refractiva tanto para la corrección de la afaquia unilateral $(40,41)$ como en casos de queratoplastia penetrante combinada simultáneamente con la extracción intracapsular de catarata (41) o para la epiqueratofaquia en cataratas congénitas y traumáticas (42). Koenig y cols (37) examinan cinco pacientes adultos intervenidos con córneas de donantes de 3 meses de edad o menos que muestran una miopía inducida, atribuyéndolo al elevado poder refractivo de la córnea infantil. El promedio de refracción esférica preoperatorio era de +1,67 D cambiando después de la intervención a valores de refracción negativos, con una media de $-7,35 \mathrm{D}$, lo que supone una miopización de aproximadamente 9 dioptrías, mostrando todos ellos una marcada curvatura corneal, con un promedio de 57,67 D. De este modo el injerto corneal neonato provocaría en las queratoplastias unilaterales una marcada anisometropía miópica que haría incluso difícil la corrección con gafas o incluso la adaptación de una lente de contacto. Aunque la reducción a 0,25 mm o incluso eliminación de la disparidad en el diámetro del injerto donante obtenido por la cara endotelial y la trepanación del receptor, provocaría teóricamente una disminución la incurvación del injerto y compensaría parcialmente la consiguiente miopización, podría por el contrario crear problemas en la aposición donante/receptor y en la aplicación correcta de la sutura dada la imprevisible respuesta de un tejido tan elástico.

\section{C) Problemas clínicos}

Aunque la alta densidad endotelial de la córnea infantil presupone una teórica mayor viabilidad del injerto, Palay y cols (43) encuentran una mayor incidencia de episodios de rechazo inmunológico (37\%), frente al grupo control $(6,9 \%)$ en la serie de 29 ojos en la que emplean córneas donantes inferiores a 6 años, con independencia de la edad del receptor y el diagnóstico, sugiriendo que esa res- puesta podría deberse a la expresión de mayores niveles de antígenos de histocompatibilidad en el tejido pediátrico. No obstante la incidencia de fracaso del trasplante fue similar a la obtenida con tejido adulto (6,9\% en ambos grupos), atribuyéndolo a que la mayor población endotelial, contrarrestaría la pérdida celular tras un episodio de rechazo, permitiendo finalmente obtener un injerto transparente. En este sentido, las ventajas e inconvenientes, en relación al resultado final en ambos grupos, serían equiparables.

En nuestros dos casos no se produjeron incidencias intraoperatorias reseñables durante la trepanación o la sutura y el escaso traumatismo quirúrgico queda confirmado por el mantenimiento al año de la intervención, en la primera paciente de una densidad endotelial en el injerto $\left(4.941 \mathrm{cel} / \mathrm{mm}^{2}\right)$, prácticamente idéntico a la medición obtenida en la microscopía especular preoperatoria (4.950 $\left.\mathrm{cel} / \mathrm{mm}^{2}\right)$ con una ligera reducción $\left(4.300 \mathrm{cel} / \mathrm{mm}^{2}\right)$ al año y medio.

La respuesta refractiva fue bastante diferente de la que refiere comúnmente la literatura por el empleo de la córnea de neonatos. El hecho más destacable en el postoperatorio fue la inesperada fuerte hipermetropización frente a la miopía esperable por la habitual mayor curvatura de la córnea en los primeros meses de vida que indican los datos bibliográficos precedentes, llamando también la atención el moderado astigmatismo postoperatorio. El primer fenómeno podría atribuirse o bien a que la córnea donante ya tuviera estos valores previamente, dato imposible de confirmar o a que por el hecho de la igualdad entre el diámetro del injerto donante y de la trepanación del receptor y por la mayor adaptabilidad y elasticidad del tejido, la tensión uniforme de la sutura continua, excesivamente apretada durante el reajuste provocó la aplanación del injerto. El bajo astigmatismo inicial podría deberse al reajuste de la sutura bajo control queratoscópico intraoperatorio y a la buena adaptabilidad del injerto en el lecho receptor. Aunque el defecto hipermetrópico (tanto el componente cilíndrico como el esférico) se redujo notablemente en los meses siguientes a la intervención, el astigmatismo experimentó una marcada variación tras la escisión de la sutura. En el primer paciente se efectuó al año de la operación, lo que cuestiona su oportunidad en ese plazo convencional, obligando a su corrección quirúrgica mediante queratotomías arcuatas y puntos de refuerzo consiguiéndose, no obstante, una notable reducción de 
cerca de 8 dioptrías que permitió alcanzar una excelente visión de $\mathrm{V}=1$ con la corrección de gafas y adaptar sin problemas una lente de contacto. En el segundo paciente se produjo un episodio de rechazo endotelial a los 8 meses del trasplante y muy poco después, posiblemente por una más rápida cicatrización, se produjo el aflojamiento de la sutura y su rotura fortuita obligando a una escisión precoz tras la que, igualmente, se comprobó una fuerte elevación del astigmatismo hipermetrópico. Pese al enérgico tratamiento del rechazo, tópico y sistémico, el cuadro ha resultado irreversible contrastando con nuestra experiencia previa en casos de queratocono, en los que se consiguió su remisión en más de un $95 \%$. Aún mostrando una leve remisión inicial, a los 12 meses de su aparición ha persistido el edema difuso del injerto por lo que evidentemente no se ha planteado la corrección quirúrgica del astigmatismo ante la perspectiva de realizar en un próximo futuro una nueva queratoplastia.

Con todo lo anterior concluimos que el injerto corneal de donante neonato puede originar un fuerte defecto hipermetrópico inicial, contrario a la supuesta miopización que indica la escasa bibliografía, que parece reducirse paulatinamente.

El astigmatismo moderado conseguido tras la sutura continua y su reajuste con control queratoscópico intraoperatorio experimenta un fuerte cambio tras la escisión, sugiriendo que la persistencia de una marcada elasticidad y adaptabilidad del injerto provoca una mayor incurvación y una reducción de la hipermetropía al eliminarse la presión uniforme y equilibrada de los puntos.

Al tratarse de receptores jóvenes, la más rápida cicatrización puede provocar un aflojamiento precoz de la sutura.

Pese a la mayor densidad endotelial, el riesgo de rechazo irreversible parece más elevado, presumiblemente por una mayor capacidad inmunogénica.

A falta de estudios más amplios y a pesar de su aparente buena calidad tisular, el empleo de córnea del neonato y lactante, en la queratoplastia penetrante, resulta todavía cuestionable, debido a su impredecible respuesta refractiva e inmune.

\section{BIBLIOGRAFÍA}

1. Foster RK, Fine M. Relation of donor age to succes in penetrating keratoplasty. Arch Ophthalmol 1971; 85: 4247.
2. Jenkins MS, Lempert SL, Brown SI. Significance of donor age in penetrating keratoplasty. Ann Ophthalmol 1979; 11: 974-976.

3. Chipman ML, Basu PK, Willett PJ, Cherry PM, Slomovic $A R$. The effects of donor age and cause of death on corneal graft survival. Acta Ophthalmol (Copenh) 1990; 68: 537-542.

4. Brightbill FS. Corneal Surgery. Theory, Technique and Tissue. Second Edition. Mosby. 1993; 531-548.

5. al-Umran $K U$, Pandolfi MF. Corneal diameter in premature infants. Br J Ophthalmol 1992; 76: 292-293.

6. Tucker SM, Enzenauer RW, Levin AV, Morin JD, Hellmann J. Corneal diameter, axial length, and intraocular pressure in premature infants. Ophthalmology 1992; 99: 1296-1300.

7. Sorsby A, Sheridan M. Changes in the refractive power of the cornea during growth; observations on the rabbit. $\mathrm{Br}$ J Ophthalmol 1953; 37: 555-557.

8. Weekers R, Grieten J, Lavergne G. Study of dimensions of the anterior chamber of the human eye. 1. Biometric considerations. Ophthalmologica 1961; 142: 650-662.

9. Blomdahl S. Ultrasonic measurements of the eye in the newborn infant. Acta Ophthalmol (Copenh) 1979; 57: 1048-1056.

10. Saunders KJ. Early refractive development in humans. Surv Ophthalmol 1995; 40: 207-216.

11. Insler MS, Cooper HD, May SE, Donzis PB. Analysis of corneal thickness and corneal curvature in infants. CLAO J 1987; 13: 182-184.

12. Gernet $H$. Axis lenght and refraction of the living eye in newborn infants. Albrecht Von Graefes Arch Ophthalmol 1964; 166: 530-536.

13. Ehlers N, Sorensen T, Bramsen T, Poulsen EH. Central corneal thickness in newborns and children. Acta Ophthalmol (Copenh)1976; 54: 285-290.

14. Donzis PB, Insler MS, Gordon RA. Corneal curvatures in premature infants. Am J Ophthalmol 1985; 99: 213215.

15. Inagaki $Y$. The rapid change of corneal curvature in the neonatal period and infancy. Arch Ophthalmol 1986; 104: 1026-1027.

16. Inagaki $Y$, Tanaka M, Hirano A, Magatani $H$, Kato $K$, Nakajima A. Rearranged automated keratometer for newborn infants and patients in supine position. Am J Ophthalmol 1985; 99: 664-666.

17. Mandell RB. Corneal contour of the human infant. Arch Ophthalmol 1967; 77: 345-348.

18. Gordon RA, Donzis PB. Refractive development of the human eye. Arch Ophthalmol 1985; 103: 785-789.

19. Kotulak JC, Brungardt T. Age-related changes in the cornea. J Am Optom Assoc, 1980; 51: 761-765.

20. Duke-Elder S, Cook C. System of Ophthalmology. Vol. III. Normal and Abnormal Development Part. I. In: DukeElder S. Embriology. Henry London: Henry Kimpton. 1963; 306-307.

21. Laule A, Cable MK, Hoffman CE, Hanna C. Endothelial cell population changes of human cornea during life. Arch Ophthalmol 1978; 96: 2031-2035.

22. Murphy C, Alvarado J, Juster R, Maglio M. Prenatal and postnatal cellularity of the human corneal endothelium. A quantitative histologic study. Invest Ophthalmol Vis Sci 1984; 25: 312-322. 
23. Bahn CF, Glassman RM, McCallum DK, Lillie JH, Meyer $R F$, Robinson BJ, et al. Postnatal development of corneal endothelium. Invest Ophthalmol Vis Sci 1986; 27: 44-51.

24. Speedwell L, Novakovic P, Sherrard ES, Taylor DS. The infant corneal endothelium. Arch Ophthalmol 1988; 106: 771-775.

25. Muller A, Doughty MJ. Assessment of corneal endothelial cell density in growing children and its relationship to horizontal corneal diameter. Optom Vis Sci 2002; 79: 762-770.

26. Muller A, Doughty MJ, Wright L. Reassessment of the corneal endothelial cell organisation in children. Br J Ophthalmol 2000; 84: 692-696.

27. Waring GO 3rd, Bourne WM, Edelhauser HF, Kenyon KR. The corneal endothelium. Normal and pathologic structure and function. Ophthalmology 1982; 89: 531590.

28. Sherrard ES, Novakovic P, Speedwell L. Age-related changes of the corneal endothelium and stroma as seen in vivo by specular microscopy. Eye 1987; 1: 197-203.

29 .Dougthy MJ, Muller A, Zaman ML. Assessment of the realiability of human corneal endothelial cell-density estimates using a noncontact specular microscope. Cornea 2000; 19: 148-158.

30. Ko MK, Kim JG, Chi JG. Cell density of the corneal endothelium in human fetus by flat preparation. Cornea 2000; 19: 80-83.

31. Ko MK, Park WK, Lee JH, Chi JG. A histomorphometric study of corneal endothelial cells in normal human fetuses. Exp Eye Res 2001; 72: 403-409.

32. Laing RA, Sandstrom MM, Berrospi AR, Leibowitz HM. Changes in the corneal endothelium as a function of age. Exp Eye Res 1976; 22: 587-594.
33. Wilson RS, Roper-Hall MJ. Effect of age of the endothelial cell count in the normal eye. Br J Ophthalmol 1982; 66: 513-515.

34. Hiles DA, Biglan AW, Fetherolf EC. Central corneal endothelial cell counts in children. J Am Intraocul Implant Soc 1979; 5: 292-300.

35. Nucci P, Brancato R, Mets MB, Shevell SK. Normal endothelial cell density range in childhood. Arch Ophthalmol 1990; 108: 247-248.

36. Abib FC, Barreto Junior J. Behavior of corneal endothelial density over a lifetime. J Cataratact Refract Surg 2001; 27: 1574-1578.

37. Koenig S, Graul E, Kaufman HE. Ocular refraction after penetrating keratoplasty with infant donor corneas. Am J Ophthalmol 1982; 94: 534-539.

38. Koenig SB. Myopic shift in refraction after penetrating keratoplasty with pediatric donor tissue. Am J Ophthalmol 1986; 101: 740-741.

39. Vannas M. Remarks on the technique of corneal transplantation. Am J Ophthalmol 1950; 33: 70.

40. Wood TO, Nissenkorn I. Infant donor corneas for penetratig keratoplasty. Ophthalmic Surg 1981; 12: 500-502.

41. Pfister RR, Breaud S. Aphakic refractive penetrating keratoplasty using newborn donor corneas. A preliminary report on an alternative approach to refractive correction. Ophthalmology 1983; 90: 1207-1212.

42. Morgan K, Stephenson GS, McDonald MB, Kaufman HE. Epikeratophakia in children. Ophthalmology 1984; 91: 780-784.

43. Palay DA, Kangas TA, Stulting RD, Winchester K, Litoff $D$, Krachmer JH. The effects of donor age on the outcome of penetrating keratoplasty in adults. Ophthalmology 1997; 104: 1576-1579. 